\title{
CBT added to tapering helped patients with chronic insomnia discontinue benzodiazepine use
}

Morin CM, Bastien C, Guay B, et al. Randomized clinical trial of supervised tapering and cognitive behavior therapy to facilitate benzodiazepine discontinuation in older adults with chronic insomnia. Am J Psychiatry 2004;161:332-42.

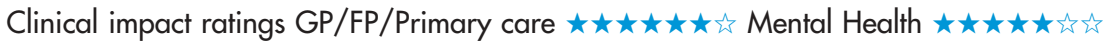

In older patients with both chronic insomnia and long term use of benzodiazepines (BDPs), is cognitive behavioural therapy (CBT) plus supervised medical tapering (SMT) (combined therapy [CT]) more effective than CBT or SMT alone for discontinuing BDPs?

METHODS

\begin{tabular}{|c|c|}
\hline & Design: randomised controlled trial. \\
\hline & Allocation: $\{$ allocation concealed $\}$ \}. $\dagger$ \\
\hline & $\begin{array}{l}\text { Blinding: blinded (technician who scored polysomnography } \\
\text { sleep stages).* }\end{array}$ \\
\hline & Follow up period: 12 months \\
\hline & $\begin{array}{l}\text { Setting: a research based sleep clinic in a university hospital in } \\
\text { Sainte-Foy, Québec, Canada. }\end{array}$ \\
\hline & $\begin{array}{l}\text { Patients: } 76 \text { patients } \geqslant 55 \text { years of age (mean age } 63 \text { y, } 50 \% \\
\text { women) with chronic insomnia (for } \geqslant 6 \text { months), impaired } \\
\text { daytime functioning or mood disturbances, and benzodiazepine } \\
\text { use (on }>50 \% \text { of nights) for } \geqslant 3 \text { months. Exclusion criteria } \\
\text { included medical or psychiatric disorders known to cause } \\
\text { insomnia, sleep apnoea, periodic limb movements during sleep } \\
\text { and other psychiatric disorders or cognitive impairment. }\end{array}$ \\
\hline & $\begin{array}{l}\text { Intervention: } 10 \text { weeks of CT }(n=27), C B T(n=24) \text {, or SMT } \\
(n=25) \text {. SMT in both CT and SMT alone groups aimed for } \\
\text { dosage reductions of } 25 \% \text { at } 2 \text { week intervals until the lowest } \\
\text { available dose of the BDP was reached. CBT ( } 10 \text { ninety minute } \\
\text { weekly sessions) was designed to reinforce the bed as a cue for } \\
\text { sleep, regularise sleep rhythm, enhance sleep efficiency, deal } \\
\text { with thoughts that could exacerbate the sleep disorder, and } \\
\text { educate about sleep and aging. }\end{array}$ \\
\hline 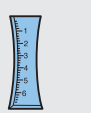 & $\begin{array}{l}\text { Outcomes: change from baseline in BDP use (frequency, } \\
\text { quantity, and drug free status) assessed immediately after } \\
\text { treatment, and at } 3 \text { and } 12 \text { months of follow up. }\end{array}$ \\
\hline$\vec{\longrightarrow}$ & $\begin{array}{l}\text { Patient follow up: all patients were included in the intention to } \\
\text { treat analyses. }\end{array}$ \\
\hline & $\begin{array}{l}\text { *See glossary. } \\
\text { †Information provided by author. }\end{array}$ \\
\hline
\end{tabular}

\section{MAIN RESULTS}

CT (compared with CBT and SMT) was associated with less frequent BDP use (number of nights of use per week) throughout the study $(p=0.02)$. At 10 weeks, more patients in the CT group than in the CBT or SMT group had discontinued BDP use; however, the groups did not differ at 3 and 12 months (table).

\section{CONCLUSION}

In older patients with chronic insomnia, cognitive behavioural therapy plus tapering was superior to either therapy alone for

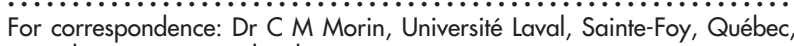
Canada.cmorin@psy.ulaval.ca

Source of funding: National Institute of Mental Health. discontinuing benzodiazepines at 10 weeks but not in the longer term (3-12 months).

Benzodiazepine discontinuation rates for cognitive behavioural therapy (CBT) plus supervised medical tapering (SMT) (combined therapy [CT]) v CBT or SMT alone in chronic insomnia*

\begin{tabular}{cllll}
\hline Follow up Comparison & Event rates & RBI $(95 \%$ CI) & NNT (CI) \\
\hline 10 weeks CT $v$ CBT & $85 \%$ v 54\% & $57 \%(9$ to 148) & $4(2$ to 18) \\
CT v SMT & $85 \%$ v $48 \%$ & $77 \%(20$ to 189) $3(2$ to 9$)$ \\
12 months CT v CBT & $59 \%$ v 33\% & $78 \%(-3$ to 250$)$ Not significant \\
CT $v$ SMT & $59 \%$ v 52\% & $14 \%(-30$ to 91) Not significant
\end{tabular}

*Abbreviations defined in glossary; RBI, NNT, and Cl calculated from data in article.

\section{Commentary}

The study by Morin et al provides 2 lessons. Firstly, $50 \%$ of eligible participants were excluded (many because of comorbid medical [mostly sleep apnoea] or psychiatric disorders), emphasising the need to screen for and treat these disorders before stopping BDPs. Secondly, the study showed that a structured discontinuation programme was effective at both stopping BDP use and improving sleep quality, even among patients who had been taking BDPs for up to 20 years.

Between group differences should be interpreted cautiously because the study did not have a "usual care" (ie, no discontinuation programme) group; the method of randomisation and the use of allocation concealment were not specified; and the patients were motivated volunteers. Also, the CBT was labour intensive, which may limit its feasibility in a typical practice environment. Previous research in this area has shown that less costly interventions, such as replacement of BDPs with other sleep aids (eg, tricyclic agents, zolpidem, and melatonin) or even a simple mailing of information about BDP discontinuation, are effective. ${ }^{1}$ Of particular note is that the CBT and SMT groups did not differ for BDP discontinuation at 12 months of follow up, a finding that is consistent with the results of another trial that did not show favourable effects of CBT over structured tapering. ${ }^{2}$ Finally, assessment of the effect on other important health outcomes such as falls and functional status was not done.

In conclusion, it is possible to successfully discontinue BDPs and improve sleep quality among motivated patients using structured discontinuation. The added value of CBT requires further study, including comparison with less costly strategies.

Patrick G O'Malley, MD, MPH, FACP Walter Reed Army Medical Center Washington, DC, USA

1 Voshaar RO, Gorgels W, Mol A, et al. Predictors of relapse after discontinuation of long-erm benzodiazepine use by minimal intervention: a 2-year follow-up study. Fam Pract 2003;20:370-2.

2 Voshaar RC, Gorgels WJ, Mol AJ, et al. Tapering off long-term benzodiazepine use with or without group cognitive-behavioural therapy: three-condition, randomised controlled trial. Br J Psychiatry 2003;182:498-504. 